\title{
Formation conditions and mechanical properties of aggregates produced in tephra- water-snow flows
}

\author{
Hirofumi Niiya ${ }^{1 *} \mathbb{D}$, Kenichi Oda ${ }^{2}$, Daisuke Tsuji ${ }^{3}$ and Hiroaki Katsuragi ${ }^{3,4}$
}

\begin{abstract}
The formation of aggregates consisting of snow, water, and tephra has been reported in small-scale experiments on three-phase flows containing tephra, water, and snow, representing lahars triggered by snowmelt. Such aggregates reduce the mobility of mud flow. However, the formation mechanism of such aggregates under various conditions has not been investigated. To elucidate the formation conditions and mechanical properties of the aggregates, we performed mixing experiments with materials on a rotating table and compression tests on the resulting aggregates with a universal testing machine in a low-temperature room at $0^{\circ} \mathrm{C}$. From experiments with varying component ratios of the mixture and tephra diameter, the following results were obtained: (i) the aggregate grew rapidly and reached maturity after a mixing time of $5 \mathrm{~min}$; (ii) the mass of aggregates increased with snow concentration, exhibiting an approximately linear relationship; (iii) single aggregates with large mass formed at lower and higher tephra concentrations, whereas multiple aggregates with smaller mass were observed at intermediate concentrations; (iv) the shape of the aggregate satisfied the similarity law for an ellipsoid; (v) the compressive mechanical behavior could be modeled by an empirical nonlinear model. The obtained mechanical properties of the aggregates were independent of the experimental conditions; (vi) scaling analysis based on the Reynolds number and the strength of the aggregates showed that the aggregates cannot form in ice-slurry lahars. Our findings suggest that low-speed lahars containing snow and ice are likely to generate aggregates, but snow and ice in the ice-slurry lahars are dispersed without such aggregates.
\end{abstract}

Keywords: Lahar, Tephra-water-snow flow, Mixing experiment, Aggregate, Compression test, Scaling analysis

\section{Introduction}

In active volcanic zones capped with snow and glaciers, snow and ice melts are produced during volcanic eruptions and rain-on-snow events. The resulting meltwater stream incorporates pyroclastic materials called tephra to become a mudflow, or lahar, which then moves rapidly downhill, causing catastrophic damage to areas far from the source (Major and Newhall 1989). A prime example of lahar hazards is an event that occurred after the November 1985 eruption of Nevado del Ruiz

\footnotetext{
*Correspondence: niiya@gs.niigata-u.ac.jp

${ }^{1}$ Center for Transdisciplinary Research, Niigata University, 8050 Ikarashi

2-no-cho, Nishi-ku, Niigata 950-2181, Japan

Full list of author information is available at the end of the article
}

in Colombia, where melting snow and ice produced a lahar with a run-out distance of more than $100 \mathrm{~km}$ that resulted in the loss of approximately 23,000 lives (Pierson et al. 1990). A massive lahar also occurred in Japan, triggered by snowmelt from the May 1926 eruption of Tokachidake (Tada and Tsuya 1927; Uesawa 2014).

The dynamics of lahars have been investigated through both laboratory experiments and numerical models (Pierson 1995, 2005). The theory of lahars is similar to that of floods and debris flows; therefore, existing models have been developed on the basis of two-phase flow involving solids and liquids. According to Pierson (2005), the flow structure is highly dependent on the sediment concentration of the flow by volume (or weight), where the three major types of flow are water flows, 
hyperconcentrated flows, and debris flows. Here, hyperconcentrated flows are defined as non-Newtonian flows that are intermediate between water flows and debris flows, in which the sediment dynamics include both saltation and suspension due to turbulence. Differences between hyperconcentrated flows and debris flows have previously been verified through field observations (Calhoun and Clague 2018).

Previous studies on lahars have typically focused on two-phase flow consisting of tephra and water; however, recent field surveys of lahars have also revealed the occurrence of snow and ice in the deposition areas (Pierson and Scott 1985; Cronin et al. 1996; Lube et al. 2009; Waythomas et al. 2013; Waythomas 2014; Kataoka et al. 2018, 2019). According to Lube et al. (2009), acidic water generated by the September 2007 eruption of Ruapehu volcano in New Zealand traveled over a snow-covered glacier, which transformed the resulting flow from a water flow into an ice-slurry lahar. Large amounts of granular snow and tephra were found in the resulting deposits. In addition, Waythomas (2014) reported that hot eruptive products generated by the March 2009 eruption of Redoubt Volcano in Alaska generated a substantial volume of meltwater that formed highly mobile flows consisting of ice, sediment, and water. These findings suggest that experimental and numerical modeling studies should consider lahars triggered by snowmelt as three-phase flows instead of two-phase flows.

Three-phase flows of tephra, water, and snow are extremely complex; even the flow structure of granular flows containing only snow particles changes with time due to the cohesion of snow related to frictional heat (Fischer et al. 2018). Moreover, the component ratio of materials in three-phase flows varies widely following snow and ice melt (Pierson and Scott 1985; Cronin et al. 1996; Lube et al. 2009). Simple experiments can be used to improve our understanding of the basic flow mechanism of ice-slurry lahars. For example, as a pioneering study, Okita et al. (2018) analyzed the flow of a mixture of tephra, water, and snow along a channel in a low-temperature room at $0{ }^{\circ} \mathrm{C}$. Here, we briefly explain their experiments because their paper is written in Japanese (Okita et al. 2018). The materials comprised tephra of 32-63 $\mu \mathrm{m}$ diameter, water, and granular snow of less than $2 \mathrm{~mm}$ diameter. The masses of tephra and water were fixed as $270 \mathrm{~g}$ and $220 \mathrm{~g}$, respectively, but the mass of snow varied in the range of 0-40 g. After mixing the materials in a vibration exciter, they were discharged into a wooden channel $(167 \mathrm{~cm}$ length, $8.4 \mathrm{~cm}$ width, $4.5 \mathrm{~cm}$ side-wall) inclined at an angle of $15^{\circ}$. In the two-phase flow consisting of tephra and water, the run-out distance and maximum frontal speed were $167 \mathrm{~cm}$ and $14 \mathrm{~cm} \mathrm{~s}^{-1}$, respectively, whereas the three-phase flow with snow stopped on the channel. Concretely, the run-out distance and maximum frontal speed with snow amounts of $10 \mathrm{~g}, 20 \mathrm{~g}$, and $30 \mathrm{~g}$ were $90 \mathrm{~cm}$ and $10 \mathrm{~cm} \mathrm{~s}^{-1}, 50 \mathrm{~cm}$ and $7 \mathrm{~cm} \mathrm{~s}^{-1}$, and $10 \mathrm{~cm}$ and $3 \mathrm{~cm} \mathrm{~s}^{-1}$, respectively. As one of the reasons for the mobility reduction, Okita et al. (2018) found the formation of aggregates consisting of snow, water, and tephra. They also proposed that the aggregates act as resistance to the flows and decrease the water content of flows.

The formation mechanism of such aggregates under various conditions is yet to be investigated. At present, no evidences of the aggregates have been reported in field surveys on ice-slurry lahars. Moreover, provided the formation of aggregates in flows, the deformation and collapse mechanisms of the aggregates remain unknown. Therefore, to elucidate the formation conditions of aggregates in three-phase (tephra-water-snow) flows, we designed a small-scale experimental system and performed mixing experiments in the fluidized state. The mechanical properties of formed aggregates were also measured using a compression machine. By varying the component ratio among the three materials, various conditions were considered, including ice-rich and water-rich lahars. The "Methods" section explains the experimental system and conditions. The "Results and discussion" section describes aggregate formation and discusses the composition and mechanical properties of the aggregates, and the scaling analysis between experiments and observations. Finally, "Conclusions" section summarizes the study and proposes future research opportunities.

\section{Methods \\ Mixing procedure}

We performed the experiments in the low-temperature room of the Research Institute for Natural Hazards and Disaster Recovery, Niigata University. The air temperature of the room was set to $0{ }^{\circ} \mathrm{C}$. The tephra, snow, and water used for the experiments were sediments collected from a pyroclastic flow at Lake Numazawa in Fukushima, granular snow cryogenically preserved after collecting natural snow, and distilled water, respectively. Additionally, we sieved the tephra and snow and classified the diameters of tephra and snow, $d_{\mathrm{t}}$ and $d_{\mathrm{s}}$, into several size distributions. The material densities of snow and water were assumed to be $\rho_{\mathrm{s}}=0.91 \mathrm{~g} \mathrm{~cm}^{-3}$ and $\rho_{\mathrm{w}}=1.00 \mathrm{~g} \mathrm{~cm}^{-3}$, respectively, whereas that of tephra $\rho_{\mathrm{t}}$ was calculated by the five-times liquid immersion method (Miwa 1970) for $d_{\mathrm{t}}$. The mean and standard deviation of $\rho_{\mathrm{t}}$ for $d_{\mathrm{t}}=32$ $63 \mu \mathrm{m}, 125-250 \mu \mathrm{m}$, and $250-500 \mu \mathrm{m}$ were $2.50 \mathrm{~g} \mathrm{~cm}^{-3}$ and $0.01 \mathrm{~g} \mathrm{~cm}^{-3}, \quad 2.66 \mathrm{~g} \mathrm{~cm}^{-3}$ and $0.03 \mathrm{~g} \mathrm{~cm}^{-3}$, and 
$2.70 \mathrm{~g} \mathrm{~cm}^{-3}$ and $0.02 \mathrm{~g} \mathrm{~cm}^{-3}$, respectively. In this study, we assumed that the material densities of tephra equal to $\rho_{\mathrm{t}}=2.50 \mathrm{~g} \mathrm{~cm}^{-3}$.

The temperatures of tephra, snow, and water were adjusted to $0^{\circ} \mathrm{C}$ and the mixing samples were enclosed in a capped cylindrical glass pot with an approximate diameter of $9 \mathrm{~cm}$ and a height of $15 \mathrm{~cm}$ (Fig. 1). The samples were placed in the pot in the following order: tephra, water, and snow, which was determined through trial and error as the best order for reproducing a homogeneous mixture by shaking. We also calculated the masses of mixing samples such that the total volume $V_{\text {total }}$ was approximately $20 \%$ of the pot volume: $V_{\text {total }}=190.9 \mathrm{~cm}^{3}$. The mixing ratio of tephra, snow, and water was determined based on the volume ratios of tephra and snow divided by itself plus water, which were termed the tephra and snow concentrations, $C_{\mathrm{t}}$ and $C_{\mathrm{s}}$,

$$
\begin{aligned}
& C_{\mathrm{t}}=\frac{V_{\mathrm{t}}}{V_{\mathrm{t}}+V_{\mathrm{w}}} \times 100, \\
& C_{\mathrm{s}}=\frac{V_{\mathrm{s}}}{V_{\mathrm{s}}+V_{\mathrm{w}}} \times 100,
\end{aligned}
$$

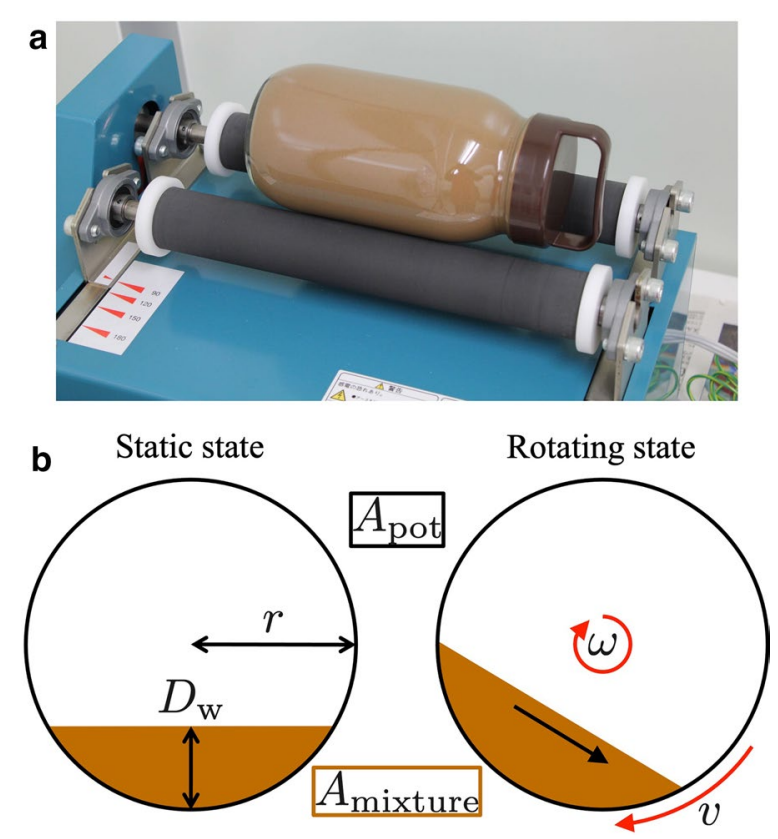

Fig. 1 Mixing experimental system: a photograph and $\mathbf{b}$ schematic images of circular cross-section. The system used to rotate the capped cylindrical glass pot containing tephra, water, and snow. The pot is automatically rotated on the rotating table (NITTO KAGAKU, ANZ-51D) at a constant speed where $V_{\mathrm{t}}, V_{\mathrm{s}}$, and $V_{\mathrm{w}}$ are the volumes of tephra, snow, and water, respectively. The relationships among concentrations, volumes, and masses of materials are described in Appendix.

To maintain a constant flow velocity of the mixture, we placed the capped cylindrical glass pot on a rotating table (NITTO KAGAKU, ANZ-51D), as shown in Fig. 1a. The rotational speed of the machine was set to $60 \mathrm{rpm}$, which corresponds to $24 \mathrm{rpm}$ of $9 \mathrm{~cm}$ diameter according to the manual, that is, the angular speed of the pot was fixed at $\omega=2.51 \mathrm{rad} \mathrm{s}^{-1}$. After rotating the pot, we removed the mixture onto a sieve with a mesh size of $2 \mathrm{~mm}$ and checked for the formation of aggregates.

\section{Flow conditions}

The water depth and the velocity of flows during pot rotation could not be measured because the tephra adhered to the surface of the wall, as shown in Fig. 1a. Instead, we estimated the water depth and the frontal speed of flows from the experimental situations and calculated the Froude number, Fr, using them. Firstly, we assumed that the maximum water depth of the mixture in the pot in the rotating state is equal to that in the static state, $D_{\mathrm{w}}$, and the frontal speed of flows is also equal to the rotating speed on the wall, $v$ (Fig. 1b). Secondly, we considered only the circular cross-section of the pot and derived $D_{\mathrm{w}}$ as follows. Using the formula of the area of a circular segment (Eq. (18) of Weisstein (2020)), the cross-sectional areas of the pot and the mixture, $A_{\text {pot }}$ and $A_{\text {mixture, are }}$ expressed as:

$$
\begin{aligned}
A_{\text {pot }}=\pi & r^{2}, \\
A_{\text {mixture }}= & r^{2} \cos ^{-1}\left(\frac{r-D_{\mathrm{w}}}{r}\right) \\
& -\left(r-D_{\mathrm{w}}\right) \sqrt{2 r D_{\mathrm{w}}-D_{\mathrm{w}}^{2}},
\end{aligned}
$$

where $r$ is the radius of the pot. As the total volume of materials was set to $20 \%$ of the pot volume, the maximum water depth of the mixture in the pot in the static state is derived from $A_{\text {mixture }} / A_{\text {pot }}=0.2$ as $D_{\mathrm{w}}=2.3 \mathrm{~cm}$. Thirdly, the rotating speed of the wall, $v$, is calculated using the radius and the angular speed of the pot, $r$ and $\omega$, as $v=r \omega=11.3 \mathrm{~cm} \mathrm{~s}^{-1}$. The values of $D_{\mathrm{w}}$ and $v$ were close to those of flows in channel-flow experiments by Okita et al. (2018), and the Froude number of the flows was approximately evaluated as $\mathrm{Fr}=v / \sqrt{D_{\mathrm{w}} g}=0.238$, where $g$ is gravitational acceleration. According to the observations of the ice-slurry lahars by Lube et al. (2009): $\mathrm{Fr}>6$ at the base of Whangehu glacier and $\mathrm{Fr}=0.6$ at a lahar monitoring site, $\mathrm{Fr}=0.238$ in our experiments corresponds to lahars far away from the source. 


\section{Heat transport}

To consider heat transport between the air and the mixture in the pot, we measured the air temperature around the rotating table, $\theta$, in response to snow melting. The amount of heat transport, $Q$, between two objects is generally proportional to the cross-sectional area of the passage, $A$, the temperature difference, $\Delta \theta$, and the elapsed time, $t$,

$$
Q=h A \Delta \theta t
$$

where $h$ is the heat transfer coefficient. In the case of heat transport from the air to the mixture in the pot, $h$ is assumed to be an unknown constant and $A$ is the surface area of the pot. The temperature of the mixture is $0^{\circ} \mathrm{C}$ as long as water and snow coexist. We also calculated the time-averaged air temperature $\theta_{\text {ave }}$ using air temperatures before and after rotating the pot, $\theta_{\text {Initial }}$ and $\theta_{\text {End }}$. Hence, $Q$ in our experiments was approximately evaluated as follows:

$$
\begin{aligned}
& Q \propto \theta_{\text {ave }} \times t, \\
& \theta_{\text {ave }}=\frac{\theta_{\text {Initial }}+\theta_{\text {End }}}{2} .
\end{aligned}
$$

\section{Measurement items of aggregates}

In this study, an aggregate was defined as an object that could be picked up without substantial deformation. Figure 2 shows typical examples of non-formation and formation of aggregates. Figure 2a shows soft sherbet-like mud remaining on the sieve, Fig. $2 b$ shows the occurrence of a distinct aggregate. When aggregates were observed, we picked up them from the sieve and measured the number of aggregates, $N$, and the mass of each aggregate, $m$, on a scale. The observed aggregates

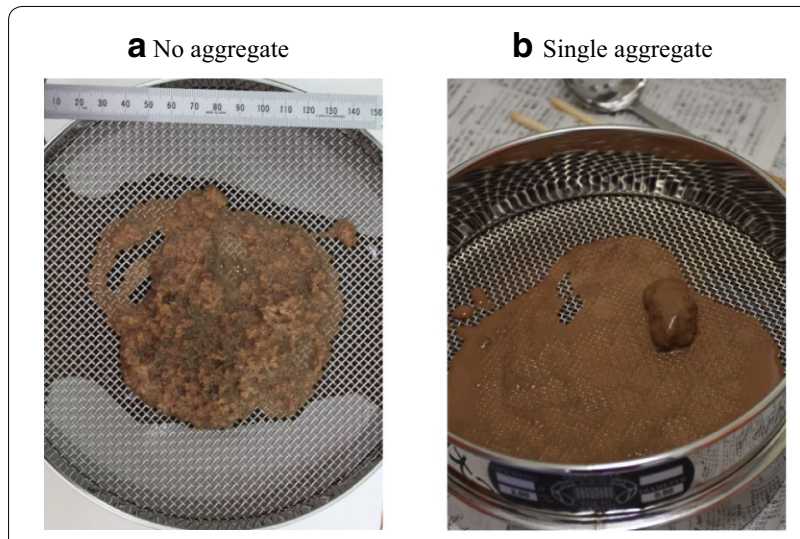

Fig. 2 Photographs of the resulting mixture. Mixture removed onto a sieve after rotating the pot: $\mathbf{a}$ soft sherbet-like mud and $\mathbf{b}$ harder aggregate consisting of tephra, water, and snow appeared similar to a rounded stone, as shown Fig. $2 \mathrm{~b}$. To evaluate the shape of each aggregate, we measured the length, $L$, width, $W$, and height, $H$, with a ruler, where the length and width of the horizontal size were divided by $L \geq W$. Continuously, we compressed the aggregates to determine their mechanical properties. Details of the compression tests are provided in the subsequent subsection. To confirm the mass composition in the aggregate, we dried the aggregate at a constant temperature of $50^{\circ} \mathrm{C}$ with an electric drying oven (ADVANTEC, DRA630DA). The mass of tephra, $m_{\mathrm{t}}$, was revealed by this process; however, the mass of water and snow, $m_{\mathrm{w}}$ and $m_{\mathrm{s}}$, were quantitatively indistinguishable from each other. Thus, we focused on the mass fraction of tephra in the aggregate: $w_{\mathrm{t}}=m_{\mathrm{t}} / m$.

\section{Compression test protocols}

To characterize the mechanical properties of the produced aggregates, we performed a set of simple compression tests. We used a universal testing machine (Imada, MTA-500N) to determine the relationship between compression stroke and force (Fig. 3). This testing machine has a capacity of a 500- $\mathrm{N}$ load cell and a resolution of $0.1 \mathrm{~N}$. A single aggregate was placed on the table of the testing machine and compressed with a constant speed of $1 / 6 \mathrm{~mm} \mathrm{~s}^{-1}$, which is the slowest compression speed of the testing machine and sufficiently slow to avoid the effect of compression inertia (we assumed quasi static compression). During compression, the force and stroke were recorded at a rate of 100 Samples $\mathrm{s}^{-1}$. Because the shape of the aggregates was highly irregular, the onset of actual compression was difficult to identify; here, we employed a compression force threshold of $F=0.2 \mathrm{~N}$

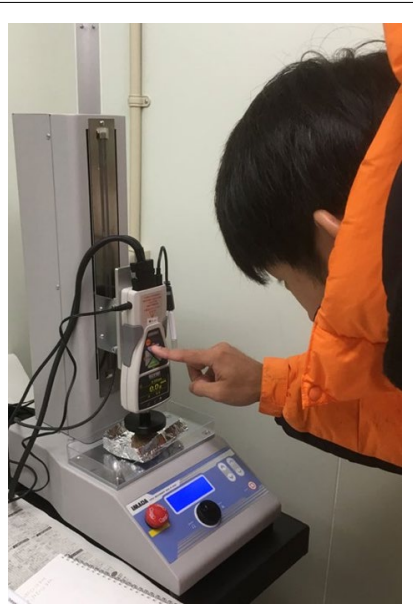

Fig. 3 Photograph of the compression machine. Experimental apparatus used to measure the compressive mechanical properties of the aggregates 
to define this point. Data were collected until $F$ reached approximately $300 \mathrm{~N}$. This maximum value of $F$ was employed to avoid breakage of the load cell. This system was used to measure the compressive force behavior of aggregates immediately after measuring their morphological dimensions.

\section{Formulation of compression test}

The mechanical behaviors of the compressed aggregates were then analyzed and modeled. An example compression curve is shown in the inset of Fig. 4a, where the compression force $F$ is plotted as a function of the compression stroke $\delta$. Aggregates of $d_{\mathrm{t}}=32-63 \mu \mathrm{m}$ (diameter), $C_{\mathrm{t}}=30 \%$ (tephra concentration), and $C_{\mathrm{s}}=10 \%$ (snow concentration) formed from tephra. The observed compression curve was highly nonlinear, indicating exponential growth. Namely, only the initial compression stage exhibited linear compression. A magnified plot of the initial stage is shown in the inset of the compression curve.

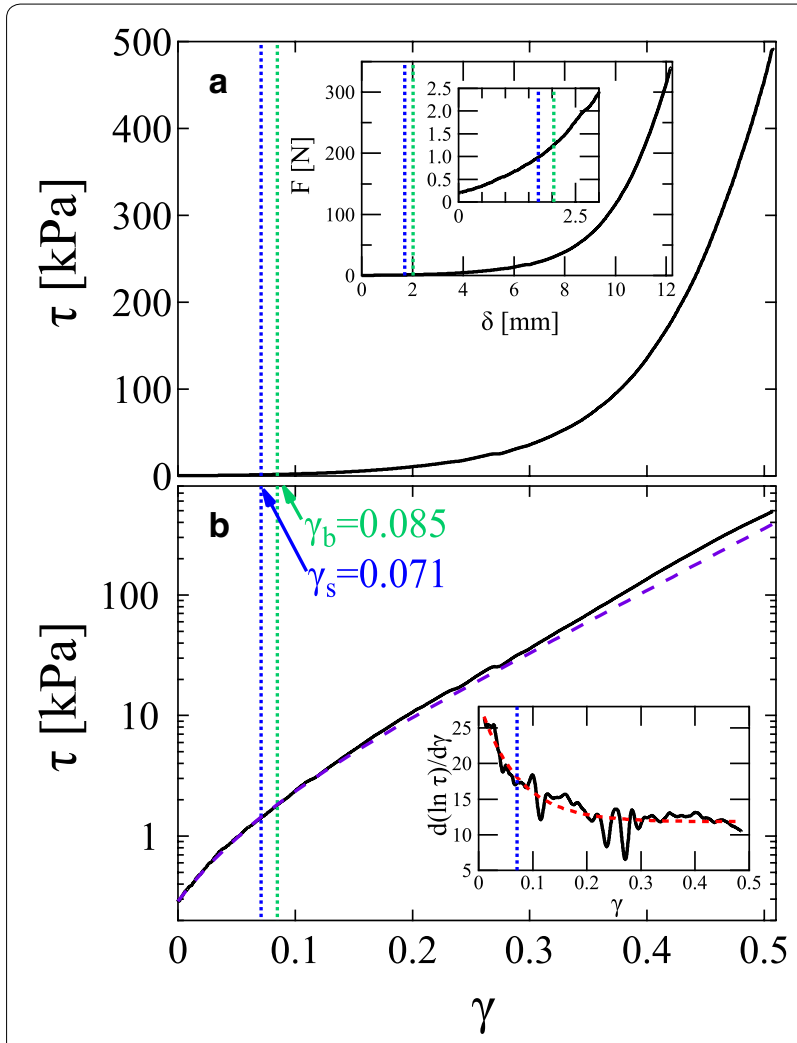

Fig. 4 Raw data from an example compression test. Parameters were $C_{\mathrm{t}}=30 \%, C_{\mathrm{s}}=10 \%$, and grain size $d_{\mathrm{t}}=32-63 \mu \mathrm{m}$. a Linear plot of the stress-strain curve and $\mathbf{b}$ semi-log plot of the same data. The inset of $\mathbf{a}$ shows the raw compression force data. The inset of $\mathbf{b}$ shows the slope of $\ln \tau$ as a function of strain $\gamma$. Purple dashed curve indicates the model of Eq. (11). Blue and green dotted lines are the levels of $\gamma_{b}$ and $\gamma_{s}$ obtained by fitting, respectively
To evaluate the mechanical properties of the aggregate, we analyzed the relationship between stress and strain. However, it was difficult to precisely evaluate stress and strain of the irregular-shaped sample; therefore, we used the dimensions of aggregates measured from photographs to normalize the force and stroke. Specifically, we approximated the aggregate by the ellipsoid; the effective area and volume of the aggregate, $S$ and $V$, were estimated using the length, width, and height of the aggregate, $L$, $W$, and $H$, as $S=\pi W L / 3$ and $V=\pi W L H / 6$. These quantities were used to define the stress $\tau$ and strain $\gamma$ as follows:

$$
\begin{gathered}
\tau=\frac{F}{S}, \\
\gamma=\frac{\delta}{H} .
\end{gathered}
$$

The stress-strain relationship is shown in Fig. 4a. Exponential-like growth was observed; therefore, we plotted the same data in a semi-log style in Fig. 4b. As expected, a linear trend was confirmed, particularly in the large $\gamma$ regime. However, slightly nonlinear behavior was also observed in the small $\gamma$ regime. To quantify this nonlinearity, the slope of the curve $d(\ln \tau) / d \gamma$ was computed (inset of Fig. 4b). The obtained slope shows exponentially asymptotic behavior. Therefore, we fit the slope curve to the following function form:

$$
\frac{d(\ln \tau)}{d \gamma}=\frac{1}{\gamma_{\mathrm{b}}}+\frac{R_{\mathrm{s}}}{\gamma_{\mathrm{s}}} \exp \left(-\frac{\gamma}{\gamma_{\mathrm{s}}}\right)
$$

This form is consistent with the asymptotic behavior shown in the inset of Fig. $4 \mathrm{~b}$ (red dashed curve). Here, $\gamma_{\mathrm{b}}$, $\gamma_{\mathrm{s}}$, and $R_{\mathrm{s}}$ are dimensionless fitting parameters.

By integrating Eq. (10), the following empirical model for compressive mechanical behavior was proposed:

$$
\tau=E_{\mathrm{b}} \exp \left[\frac{\gamma}{\gamma_{\mathrm{b}}}-R_{\mathrm{s}} \exp \left(-\frac{\gamma}{\gamma_{\mathrm{s}}}\right)\right]
$$

The parameter $E_{\mathrm{b}}$ has a stress dimension and characterizes the effective bulk compression modulus (hardness), as discussed later. Other parameters, $R_{\mathrm{s}}, \gamma_{\mathrm{b}}$, and $\gamma_{\mathrm{s}}$, indicate the ratio of the compressive moduli between bulk and surface deformation, the characteristic bulk strain, and the characteristic surface-deformation strain, respectively. The fitting curve is shown as a purple dashed curve in Fig. 4b. The proposed form is empirical and there is no clear mechanics basis for deriving the form of Eq. (11). However, all data collected in this study show similar nonlinear compression curves, implying that this behavior is universal. Thus, we employed this empirical model to discuss the mechanical properties of aggregates. The 
Table 1 List of experimental conditions

\begin{tabular}{|c|c|c|c|c|c|}
\hline Type & $d_{t}(\mu \mathrm{m})$ & $C_{\mathrm{t}}(\%)$ & $C_{s}(\%)$ & $t(\min )$ & $\begin{array}{l}\text { Number } \\
\text { of runs }\end{array}$ \\
\hline EXP1 & $32-63$ & 33 & 9 & $\begin{array}{r}0,1,3,5 \\
10,20 \\
40,60\end{array}$ & 3 \\
\hline EXP2 & $32-63$ & 33 & $1,5,9,13,17$ & 20 & 1 \\
\hline \multirow[t]{3}{*}{ EXP3 } & $32-63$ & $8,10,15$ & 10 & 5 & 2 \\
\hline & & $0,1,30$ & & & 3 \\
\hline & & 5,20 & & & 4 \\
\hline EXP4 & $125-250$ & $\begin{array}{c}5,10,15,20,25 \\
30,40\end{array}$ & 10 & 5 & 2 \\
\hline EXP5 & $250-500$ & $\begin{array}{c}10,15,20,25 \\
30,40\end{array}$ & 10 & 5 & 2 \\
\hline
\end{tabular}

Tephra diameter, tephra and snow concentrations for water volume, and the rotation time are denoted by $d_{\mathrm{t}}, C_{\mathrm{t}}$ and $C_{\mathrm{s}}$, and $t$, respectively

parameter values $\left(E_{\mathrm{b}}, R_{\mathrm{s}}, \gamma_{\mathrm{b}}, \gamma_{\mathrm{s}}\right)$ can be obtained through least-square fitting to the experimental data.

\section{Experimental conditions}

All experimental conditions are listed in Table 1. The experiments were categorized into five types: EXP1, EXP2, and EXP3-5 were performed to elucidate the effects of rotation time, $t$, snow concentration, $C_{\mathrm{S}}$, tephra concentration, $C_{\mathrm{t}}$, and tephra diameter, $d_{\mathrm{t}}$, respectively, on aggregate formation. All other experimental parameters were fixed as follows: diameter of snow, $d_{\mathrm{s}}=1-2 \mathrm{~mm}$, total volume of mixing samples, $V_{\text {total }}=190.9 \mathrm{~cm}^{3}$, and angular speed of the pot $\omega=2.51 \mathrm{rad} \mathrm{s}^{-1}$.

\section{Results and discussion \\ Effect of rotation time}

Figure 5 shows the number and mass of aggregates, $N$ and $m$, measured at each rotation time of the pot, $t$, in EXP1, where the tephra diameter, tephra concentration, and snow concentration were fixed as $d_{\mathrm{t}}=32-63 \mu \mathrm{m}$, $C_{\mathrm{t}}=33 \%$, and $C_{\mathrm{s}}=9 \%$, respectively. For $t=0 \mathrm{~min}$, no aggregate formation was observed (i.e., $N=0$ ) because the mixture was very soft (similar to a sherbet), as shown in Fig. 2a. This lack of aggregate formation also occurred during one run of $t=1 \mathrm{~min}$; nevertheless, aggregates were found at all runs of $t \geq 3 \mathrm{~min}$ (Fig. 5a). Except for $N=2$ at one run of $t=20 \mathrm{~min}$, only a single aggregate was formed by pot rotation under these experimental conditions. According to the mean values of $m$ (Fig. 5b), the aggregates grew rapidly in the early stage, with $m$ reaching a peak at $t=5 \mathrm{~min}: m \approx 45 \mathrm{~g}$. After $t=5 \mathrm{~min}$, the mass of the aggregate gradually decreased with time. Therefore, the evolution of $m$ in our experimental system was divided into two stages: a growth stage at $t \leq 5 \mathrm{~min}$

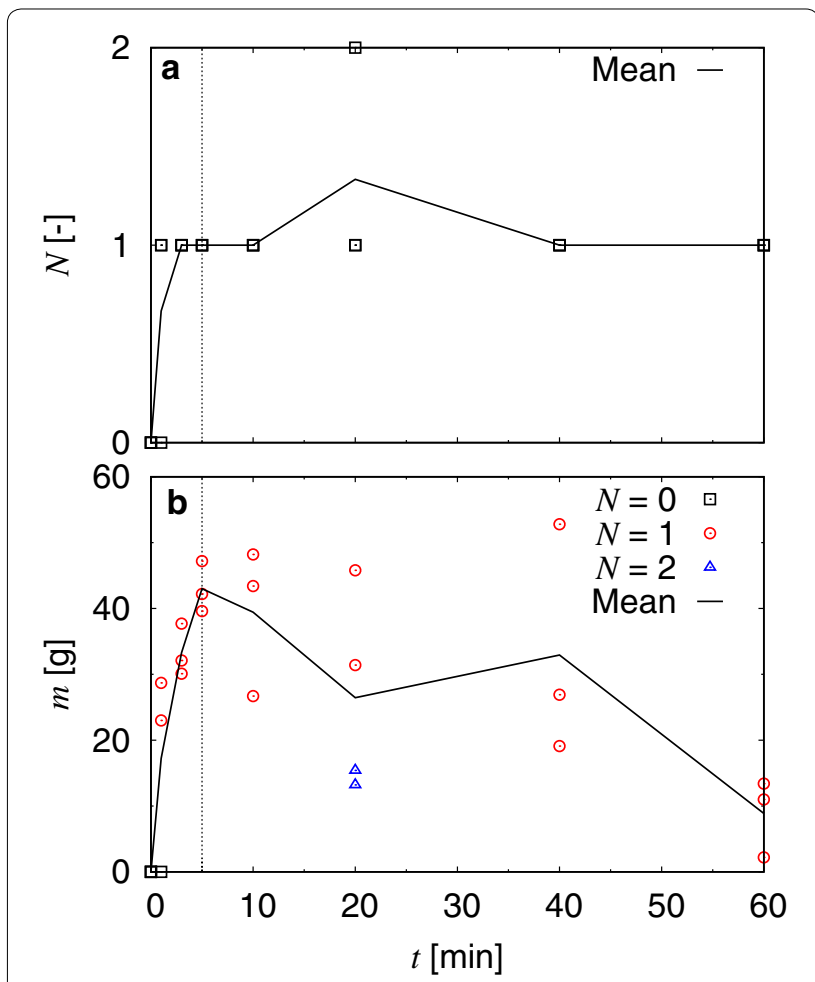

Fig. 5 Aggregate formation according to mixing time. Influence of rotation time, $t$, on aggregate formation in EXP1 $\left(d_{t}=32-63 \mu \mathrm{m}\right.$, $C_{t}=33 \%$, and $C_{s}=9 \%$ ): a number of aggregates, $N$, and $\mathbf{b}$ mass of aggregate, $m$. The vertical dashed line indicates $t=5 \mathrm{~min}$, which is the boundary between the growth and decline stages of the aggregate

and a decline stage at $t>5 \mathrm{~min}$. Note that, in some runs, the peak $m$ continued until $t=40 \mathrm{~min}$.

To further investigate the evolution of aggregate mass with time, $m(t)$, Fig. 6a shows the air temperature $\theta$ measured around the rotating table because the aggregate included snow. Although $\theta \leq 0^{\circ} \mathrm{C}$ in most experimental runs, an increase in $\theta$ was confirmed at long rotation times of $40 \mathrm{~min}$ and $60 \mathrm{~min}$. This heating was generated by operation of the rotating table. Figure $6 \mathrm{~b}$ shows the relationship between the mass of the aggregate, $m$, and the indicator of heat transport from the air to the mixture in Eq. (6), $\theta_{\text {ave }} \times t$. The mass of the aggregate at $t \leq 20 \mathrm{~min}$ exhibited random scatter, whereas that at $t \geq 40 \mathrm{~min}$ was negatively correlated with $\theta_{\text {ave }} \times t$. This result suggests that snow in the aggregate melts at $\theta_{\text {ave }} \times t>0$ with a longer rotation time. Thus, the influence of air temperature on aggregate formation was negligible at $t \leq 20 \mathrm{~min}$ in our experimental system.

\section{Effect of snow concentration}

We confirmed the effect of snow concentration $C_{\mathrm{s}}$ on the formation of aggregates in EXP2. Compared with 

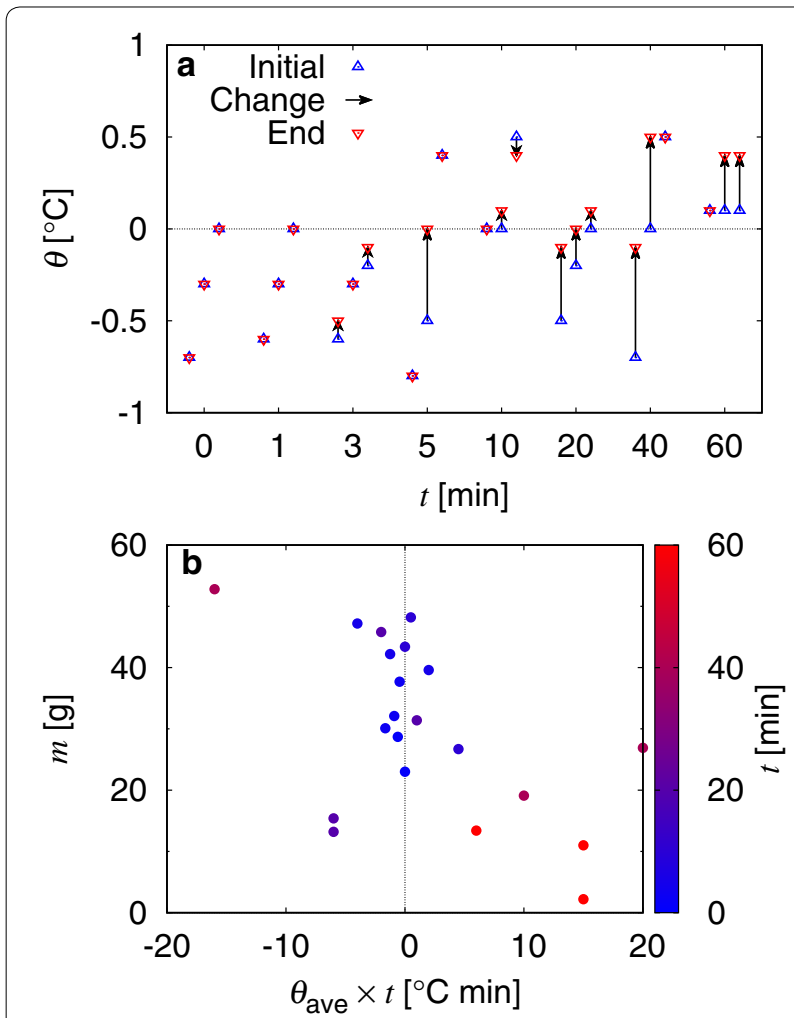

Fig. 6 Change of aggregate mass with air temperature. Effect of air temperature, $\theta$, measured around the rotating table on the evolution of the aggregate mass, $m$, with time in EXP1 $\left(d_{\mathrm{t}}=32-63 \mu \mathrm{m}\right.$, $C_{\mathrm{t}}=33 \%$, and $\left.C_{\mathrm{s}}=9 \%\right)$ : $\mathbf{a}$ change in $\theta$ at each rotation time $t$ and $\mathbf{b}$ $m$ vs. $\theta_{\text {ave }}$ times $t$. Blue up-pointing and red down-pointing triangles in a denote $\theta$ before and after rotation, respectively. The horizontal axis of $\mathbf{b} \theta_{\text {ave }} \times t$ indicates heat transport from the air into the mixture, where $\theta_{\text {ave }}$ is calculated by Eq. (7)

EXP1, EXP2 had variable $C_{\mathrm{s}}$ and a fixed rotation time of $t=20 \mathrm{~min}$ to obtain well-developed aggregates. The other experimental parameters were the same as those in EXP1; the diameter and concentration of tephra were fixed as $d_{\mathrm{t}}=32-63 \mu \mathrm{m}$ and $C_{\mathrm{t}}=33 \%$, respectively. No aggregate was observed at $C_{\mathrm{s}}=1 \%$, whereas a single aggregate formed at $C_{\mathrm{s}} \geq 5 \%$ (Fig. 7). The mass of the aggregates increased with snow concentration; the relationship between $m$ and $C_{\mathrm{s}}$ is fitted by a linear function expressed as $m=3.76 C_{\mathrm{s}}-7.16$ in our experiments. From this function, the mass of the aggregate becomes $m=0 \mathrm{~g}$ when the snow concentration approaches $C_{\mathrm{s}}=1.90 \%$. It is possible that a lower limit of $C_{\mathrm{s}}$ is required to generate an aggregate, although the number of runs was unity. In addition, $m \approx 27 \mathrm{~g}$ at $C_{\mathrm{s}}=9 \%$ is expected from the fitting line; this value corresponds to the mean of $m$ at $t=20 \mathrm{~min}$ in EXP1 (Fig 5b). According to the above results, snow is essential for aggregate formation and the mass of the aggregate increases monotonically with the amount of snow.

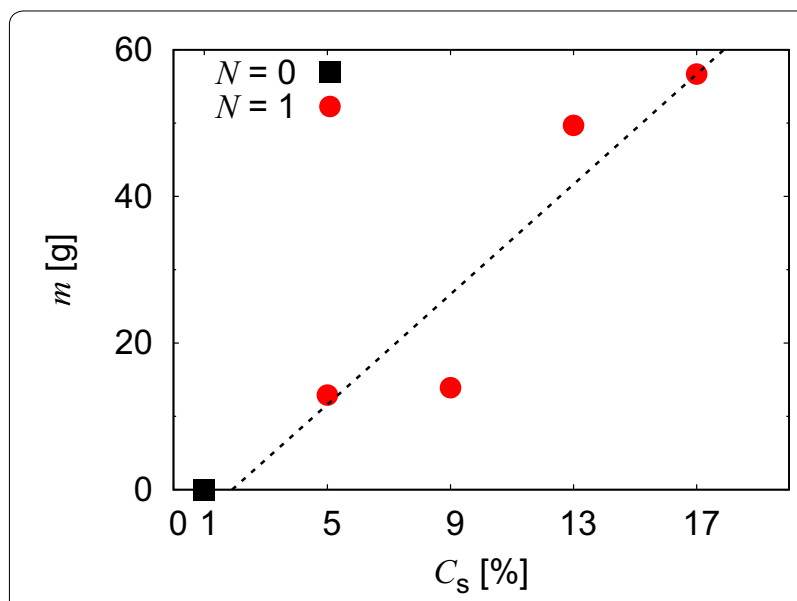

Fig. 7 Aggregate formation according to amount of snow. Influence of snow concentration, $C_{S}$, on number and mass of aggregates, $N$ and $m$, in EXP2 ( $d_{\mathrm{t}}=32-63 \mu \mathrm{m}, C_{\mathrm{t}}=33 \%$, and $\left.t=20 \mathrm{~min}\right)$. The dashed line is a fitting line: $m=3.76 C_{s}-7.16$

\section{Effect of tephra concentration and size}

The diameter and concentration of tephra in EXP1-2, $d_{\mathrm{t}}$ and $C_{\mathrm{t}}$, were set in reference to a previous experiment by Okita et al. (2018), although lahars exhibit a wide distribution of $d_{\mathrm{t}}$ and various $C_{\mathrm{t}}$ values depending on the conditions. To evaluate the effect of $d_{\mathrm{t}}$ and $C_{\mathrm{t}}$ on aggregate formation, these parameters were set as the independent variables in EXP3-5. All other parameters were fixed: rotation time $t=5 \mathrm{~min}$ and snow concentration $C_{\mathrm{s}}=10 \%$. Here, $t=5 \mathrm{~min}$ means the boundary between the growth stage and the decline stage in the evolution of aggregate mass with time (Fig. 5b), where the effect of air temperature is negligible (Fig. 6b). It is noted that the mixture of tephra and water entirely solidified at $C_{\mathrm{t}}=40 \%$ for $d_{\mathrm{t}}=32-63 \mu \mathrm{m}(\mathrm{EXP} 3)$ and $C_{\mathrm{t}}=50 \%$ for $d_{\mathrm{t}}=125-250 \mu \mathrm{m}$ (EXP4) and $d_{\mathrm{t}}=250-500 \mu \mathrm{m}$ (EXP5). In addition, tephra with $d_{\mathrm{t}}=1-2 \mathrm{~mm}$ and water were immiscible in our experimental system.

Figure 8 shows the number and mass of aggregates, $N$ and $m$, measured in EXP3-5, respectively. The aggregate in EXP3 was found at all runs of $C_{\mathrm{t}} \geq 5 \%$; however, it formed even without tephra $\left(C_{\mathrm{t}}=0 \%\right)$. The number of aggregates in EXP3 increased with an increase of the tephra concentration from $C_{\mathrm{t}}=0 \%$ to $C_{\mathrm{t}}=15 \%$; a further increase of tephra concentration caused the formation of a single aggregate $(N=1)$ (Fig. 8a). Furthermore, the mean aggregate mass in EXP3 appeared to increase with tephra concentration, but the mass of aggregates fluctuated substantially in the range of $C_{\mathrm{t}}=1-15 \%$ (Fig. 8b). The change in the number of aggregates with tephra concentration, $N\left(C_{\mathrm{t}}\right)$, in EXP4-5 was similar to that in EXP3. Additionally, we determined the lower limit of $C_{\mathrm{t}}$ for aggregate formation. Due to the increase 


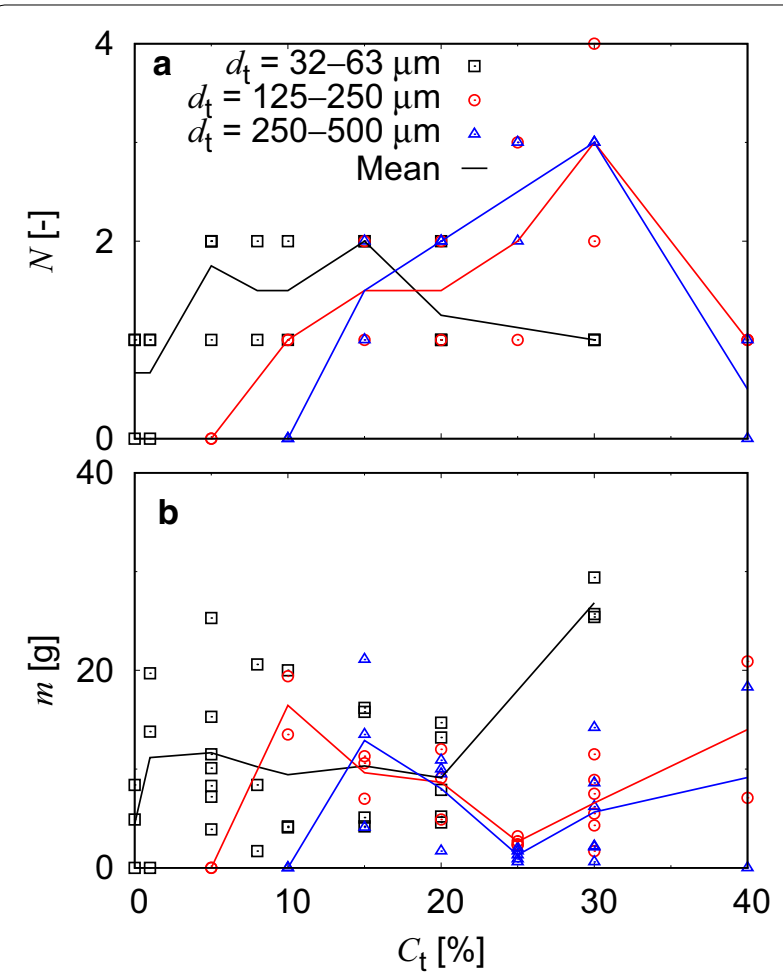

Fig. 8 Aggregate formation according to amount of tephra. Influence of tephra concentration, $C_{\mathrm{t}}$, and diameter, $d_{\mathrm{t}}$, on aggregate formation in EXP3-5 ( $C_{s}=10 \%$ and $\left.t=5 \mathrm{~min}\right)$ : a number of aggregates, $N$, and $\mathbf{b}$ mass of aggregate, $m$. Black squares, red circles, and blue triangles indicate results in EXP3, EXP4, and EXP5, respectively in tephra diameter, the range of tephra concentrations required to generate an aggregate was narrow, and the peak number of aggregates shifted to higher $C_{\mathrm{t}}$ (Fig. 8a). Compared with EXP3, aggregate mass exhibited an interesting dependence on tephra concentration, $m\left(C_{t}\right)$, in EXP4-5 (Fig. 8b), whereby large $m$ occurred at low and high $C_{\mathrm{t}}$, whereas smaller $m$ occurred at intermediate tephra concentrations. Small mass values were typically observed at $C_{\mathrm{t}}=25 \%$. Although the mechanism of aggregate regulation is unknown, the relationship between $N$ and $m$ indicated a negative correlation (Fig. 8), whereby the formation of multiple aggregates typically resulted in lower aggregate mass.

Figure 9 shows the relationships of $L$ vs. $W$ and $H$ vs. $W$. The size of the aggregate remained almost unchanged in terms of tephra diameter; nevertheless, the following observations were made regarding the shape of aggregates. In Fig. 9a, the length and width of the aggregates ranged from 1 to $5.5 \mathrm{~cm}$. A proportional relationship was observed between the length and width, $L \propto W$, at $W \leq 3 \mathrm{~cm}$, but the length was limited to $W>3 \mathrm{~cm}$. Aggregate height was less than the width

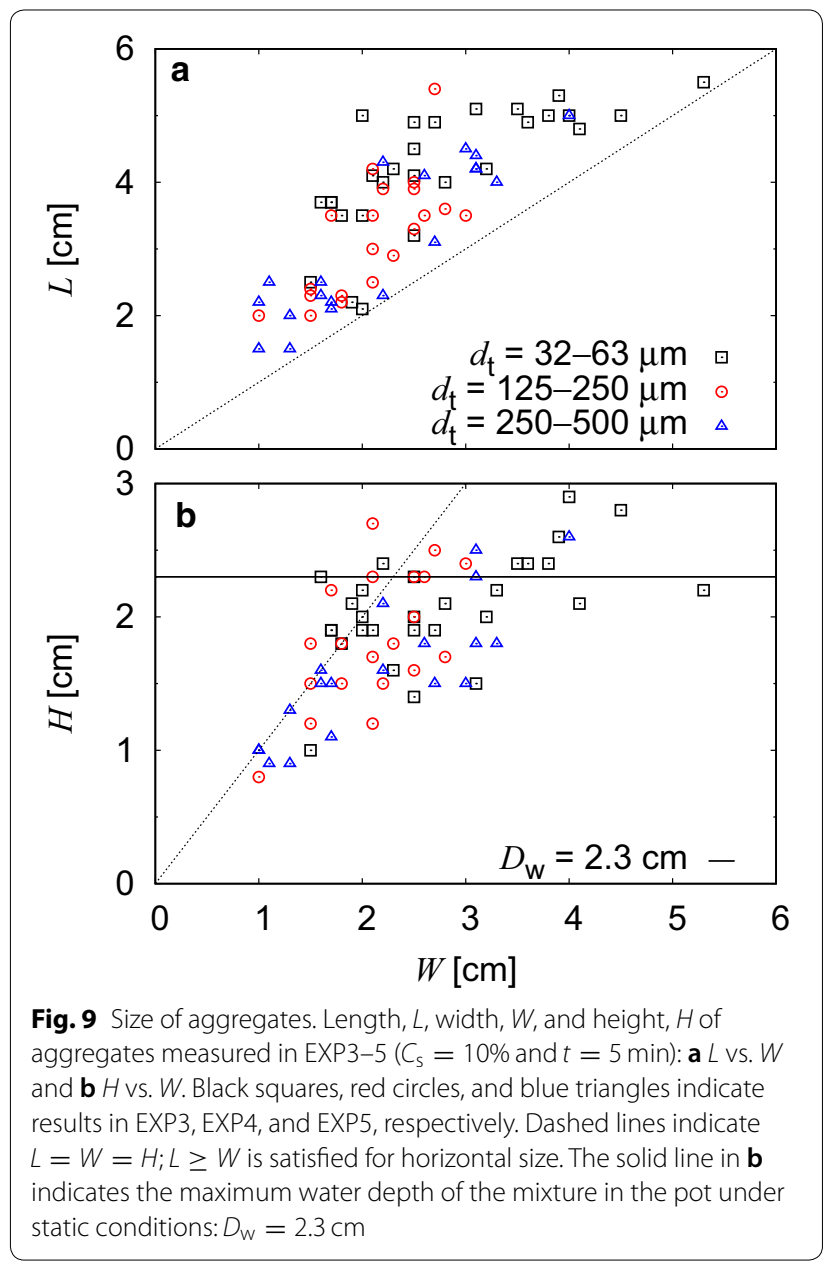

in many aggregates (Fig. 9b); that is, the relationship of $L>W>H$ held. The height was also proportional to the width, $W \propto H$, but $H$ appeared to stop increasing when it exceeded the maximum water depth of the mixture in the pot in the static state, $D_{\mathrm{w}}=2.3 \mathrm{~cm}$. The height of the aggregate may have been confined by the water depth. Therefore, the above results revealed a proportional relationship among the length, width, and height of aggregates at $H<D_{\text {w }}$.

\section{Composition of aggregate}

To determine the aggregate properties, we measured the mass composition of each aggregate observed in all experiments. In this analysis, the mass composition was categorized into tephra $m_{\mathrm{t}}$ and water plus snow $m_{\mathrm{w}+\mathrm{s}}$ because water and snow were inseparable owing to technical difficulties. The mass composition can be converted into the volume composition using the material densities of tephra, water, and snow as known values: $\rho_{\mathrm{t}}=2.50 \mathrm{~g} \mathrm{~cm}^{-3}, \rho_{\mathrm{w}}=1.00 \mathrm{~g} \mathrm{~cm}^{-3}$, and $\rho_{\mathrm{s}}=0.91 \mathrm{~g} \mathrm{~cm}^{-3}$. Hereafter, we focused on the mass 
fraction of tephra $w_{\mathrm{t}}=m_{\mathrm{t}} / m$, where $m$ is the aggregate mass.

Figure 10 shows the composition of each aggregate in EXP1-2. The horizontal axis in Fig. 10a, b are the rotation time, $t$, and snow concentration, $C_{\mathrm{s}}$, respectively. In Fig. 10a, the run number is also displayed as additional information. Although aggregates with various $m$ were observed with different values of $t$ and $C_{\mathrm{S}}$, the tephra constituted approximately one half of the total mass of aggregate. Hence, mass fractions of tephra ranged from $w_{\mathrm{t}}=0.4-0.6$ and were independent of the aggregate mass (Fig. 10). In both EXP1 and EXP2, the diameter and concentration of tephra were fixed: $d_{\mathrm{t}}=32-63 \mu \mathrm{m}$ and $C_{\mathrm{t}}=33 \%$. If the aggregate develops by the adhesion of snow, a fluid mud of tephra and water will be included in the aggregate; during the experiments, we observed abundant granular snow at the surface and interior of the aggregate. Thus, the tephra concentration is believed to be related to the mass fraction of tephra.

The above hypothesis was verified by analyzing the data of EXP3-5, where the diameter and concentration of tephra, $d_{\mathrm{t}}$ and $C_{\mathrm{t}}$, were the variables. The mass composition of tephra and water plus snow in the aggregates, $m_{\mathrm{t}}$ and $m_{\mathrm{w}+\mathrm{s}}$, in EXP3, EXP4, and EXP5 is shown in Fig. 11a-c, respectively. Compared with EXP1-2, as

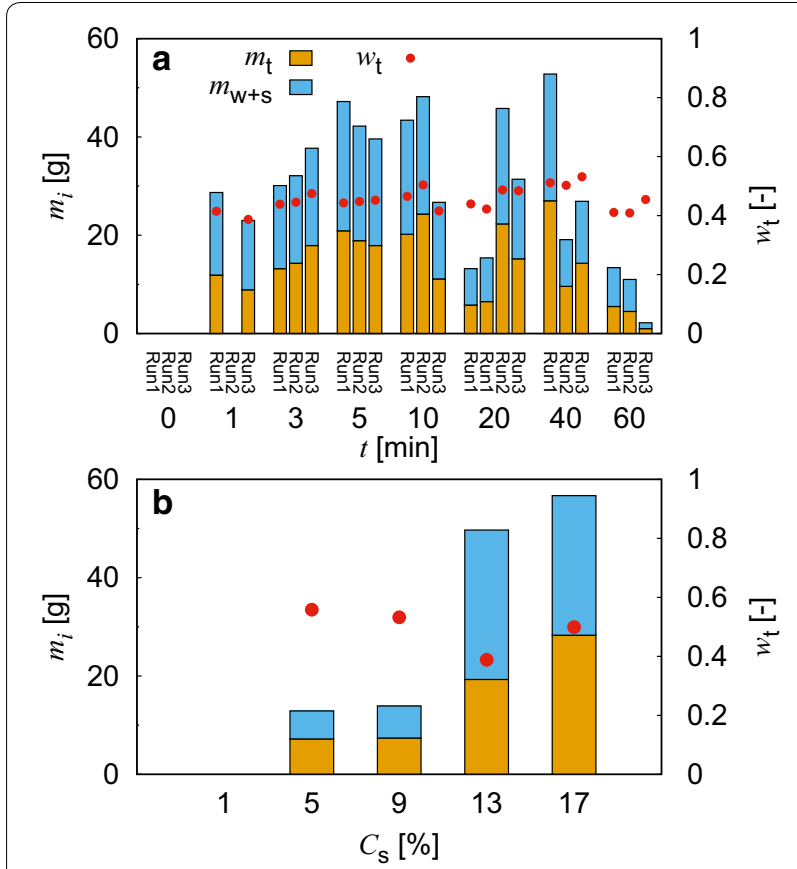

Fig. 10 Composition of aggregates produced in EXP1-2. Mass composition, $m_{i}$, and mass fraction of tephra, $w_{t}$, in aggregates: a effect of rotation time, $t\left(\right.$ EXP $1: d_{\mathrm{t}}=32-63 \mu \mathrm{m}, C_{\mathrm{t}}=33 \%$, and $\left.C_{s}=9 \%\right)$ and $\mathbf{b}$ effect of snow concentration, $C_{s}\left(\right.$ EXP2: $d_{t}=32$

$-63 \mu \mathrm{m}, C_{\mathrm{t}}=33 \%$, and $t=20 \mathrm{~min}$ ). Yellow and aqua bars denote the mass of tephra and water plus snow, $m_{\mathrm{t}}$ and $m_{\mathrm{w}+\mathrm{s}}$, respectively

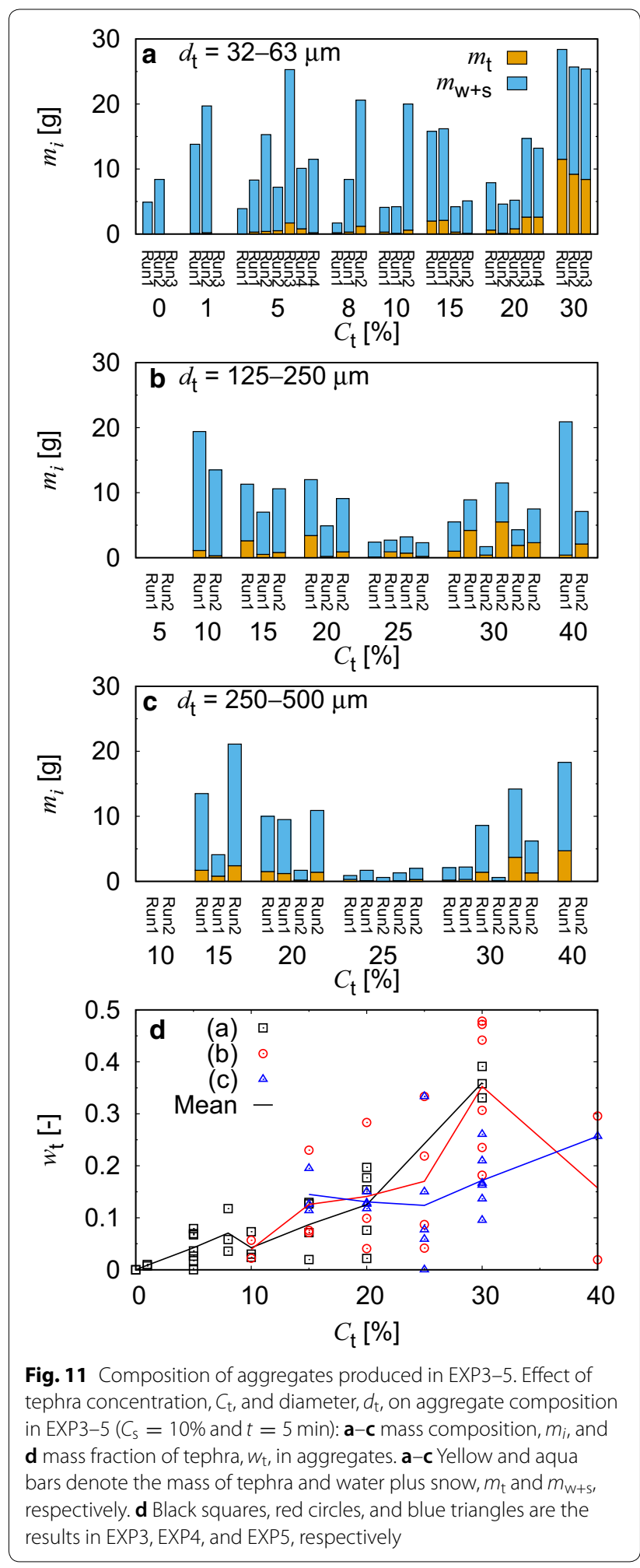

shown in Fig. 10, the ratio of tephra to the total mass of aggregates varied considerably with tephra concentration. Figure $11 \mathrm{~d}$ shows the mass fraction of tephra, $w_{\mathrm{t}}$, 
in EXP3-5. The mass fraction of tephra in EXP3 using $d_{\mathrm{t}}=32-63 \mu \mathrm{m}$ increased with tephra concentration from $w_{\mathrm{t}}=0$ to $w_{\mathrm{t}}=0.4$, which supports our hypothesis. This relationship between $w_{\mathrm{t}}$ and $C_{\mathrm{t}}$ was also observed in EXP4 for larger $d_{\mathrm{t}}=125-250 \mu \mathrm{m}$, except at a high tephra concentration of $C_{\mathrm{t}}=40 \%$. Conversely, in EXP5 with the largest $d_{\mathrm{t}}=250-500 \mu \mathrm{m}$, the mass fraction of tephra was approximately constant at $w_{\mathrm{t}} \approx 0.15$.

One reason for the change in the mass fraction of tephra with tephra diameter is believed to be a change of matric potential according to the material size, such as the moisture characteristic curve (Klute 1986). In other words, as we removed the aggregate from the pot, the aggregate was exposed to air intrusion on the sieve. Thus, the aggregate should hold the liquid mud of tephra and water at an appropriate tephra diameter. These analyses indicate that the mass fraction of tephra in the aggregate is related not only to the tephra concentration, but also to the tephra diameter. Note that all analyses of aggregates were conducted outside the mud flow.

\section{Mechanical characterization}

By fitting all obtained compression curves in Eq. (11), we evaluated the effects of different characteristic parameters: $E_{\mathrm{b}}, R_{\mathrm{s}}, \gamma_{\mathrm{b}}$, and $\gamma_{\mathrm{s}}$. In Fig. 12, the obtained parameter values are displayed against the tephra concentration, $C_{\mathrm{t}}$. As shown in Fig. 12, any clear parameter dependence of the characteristic quantities could not be confirmed. Instead, all quantities exhibited approximately similar values independent of the experimental conditions.

Aggregate deformation observed in the compression tests was found to be irreversible. In other words, plasticity dominated the deformation mode and the effective stress-strain curve was nonlinear. This type of compression behavior differs significantly from that of linearelastic/plastic materials. Thus, it is difficult to discuss the mechanical properties of aggregates using conventional material mechanics. Instead, we derived an empirical model, the physical meaning of which is described here, along with the characteristic quantities.

First, we focused on the large $\gamma$ regime, i.e., the late stage of compression. In this stage, the term $\exp \left(-\gamma / \gamma_{\mathrm{s}}\right)$ vanishes. As a result, the compression curve approaches that of simple exponential growth. However, below the characteristic strain $\gamma<\gamma_{\mathrm{b}}$, a linear approximation can be applied to the curve. Then, the slope (effective modulus in the relatively small $\gamma$ regime) can be estimated by $E_{\mathrm{b}} / \gamma_{\mathrm{b}}$. According to Fig. $12 \mathrm{a}$, c, the typical orders of these quantities were $E_{\mathrm{b}} \sim 10^{0} \mathrm{kPa}$ and $\gamma_{\mathrm{b}} \sim 10^{-1}$. As a consequence, $E_{\mathrm{b}} / \gamma_{\mathrm{b}} \sim 10 \mathrm{kPa}$ was obtained, which is the effective compressive strength of the aggregates, $F_{\mathrm{c}}$. Because all measured quantities were relatively insensitive

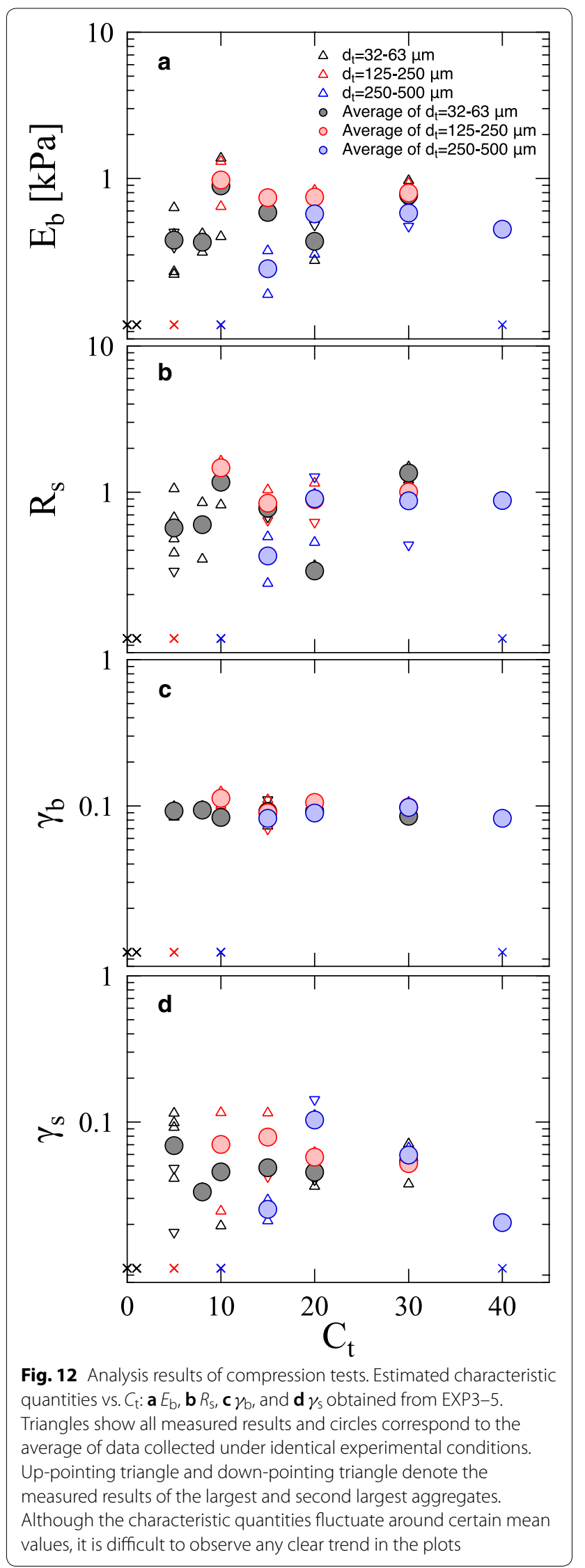


to the experimental conditions, this value is considered representative.

In the small $\gamma$ regime, the term $\exp \left(-\gamma / \gamma_{\mathrm{s}}\right)$ plays a certain role. This initial nonlinearity comes from compression of the surface roughness of the aggregates. As observed in the actual photographs, the aggregates exhibited surface roughness. Compression initiated when the compression plate reached the top surface of this roughness. However, in the early stage, only the surface roughness was flattened. After complete flattening, bulk compression dominated the compression behavior. The exponential growth of the stress curve in the late stage corresponds to this bulk compression, and early surface flattening corresponds to the asymptotic decrease of stress. Therefore, $\gamma_{\mathrm{b}}$ and $\gamma_{\mathrm{s}}$ indicate the characteristic strain for bulk compression and surface-roughness compression, respectively, revealing two modes of aggregate compression. In any case, the mechanical properties were approximately independent of the experimental conditions, which is advantageous for modeling the behavior of aggregates in an actual mud flow because it is not necessary to consider the wide variety of aggregate mechanical behaviors. However, it should be noted that the mechanical properties can vary during compression. Compression tests were conducted after picking up the aggregates and measuring their dimensions; thus, liquid water drainage during the test could affect the mechanical properties of the aggregates. In this experiment, however, we neglected such effects.

\section{Scaling analysis between experiments and observations}

Flows in small-scale experiments and natural ice-slurry lahars extremely differ from each other in terms of the scale. To evaluate the formation and the deformation of the aggregates in nature, we attempted scaling analysis based on experimental results and observational data. The scaling analysis was conducted considering two different parameters: the particle Reynolds number and the strength of aggregates. For the natural formation of aggregates, the former and the latter estimate the size and deformability of the aggregates, respectively. We used observational data of ice-slurry lahars obtained by Cronin et al. (1996) and Lube et al. (2009) in the scaling analysis.

The particle Reynolds number, $R e_{\mathrm{p}}$, is expressed using the diameter of the aggregates, $d$, as

$$
R e_{\mathrm{p}}=\frac{\rho_{\mathrm{b}} U d}{\mu},
$$

where $\rho_{\mathrm{b}}, U$, and $\mu$ are the bulk density, frontal speed, and viscosity coefficient of flows, respectively. In our experiments, the frontal speed was evaluated as the rotating speed of the wall (Fig. 1b): $\rho_{\mathrm{b}}=991-1557 \mathrm{~kg} \mathrm{~m}^{-3}$ and
$U=0.113 \mathrm{~m} \mathrm{~s}^{-1}$. The bulk density is listed in Appendix. The typical diameter of the aggregates could be set to $d=30 \mathrm{~mm}$ (Fig. 9). Although the viscosity coefficient was unknown, the particle Reynolds number in our experiments was calculated as $R e_{\mathrm{p}}=3.36-5.28 \mu^{-1}$. To estimate the diameter of the aggregates in nature, we assumed that $\mu$ and $R e_{\mathrm{p}}$ in our experiments are the same as those of natural ice-slurry lahars. Under this assumption, the diameter of the aggregates in nature is expressed using $\rho_{\mathrm{b}}$ and $U$ of observational data as

$$
d=\frac{3.36-5.28}{\left(\rho_{\mathrm{b}} U\right)_{\mathrm{obs}}} .
$$

The effective compressive strength of the aggregates, $F_{\mathrm{c}}$, was obtained from the compression test and the modeling, and the value of $F_{\mathrm{c}}$ was almost independent of the size of aggregates and the experimental conditions: $F_{\mathrm{c}}=10^{4} \mathrm{~Pa}$. Actually, the deformation and the collapse of the aggregates are expected because various forces act on the aggregates in the flows. To estimate the deformability of the aggregates in the ice-slurry lahars, we proposed the non-dimensional parameter for maintaining the aggregates. This parameter is defined as the ratio of the strength of the aggregates, $F_{\mathrm{c}}$ divided by the dynamic pressure of the fluid, $P$,

$$
\frac{F_{\mathrm{c}}}{P}=\frac{10^{4}}{\rho_{\mathrm{b}} U^{2} / 2},
$$

where $\rho_{\mathrm{b}}$ and $U$ are the bulk density and the frontal speed of the flows, respectively. Here, we assumed that the aggregates exist without deformation at $F_{\mathrm{c}} / P \gg 1$, but they collapse at $F_{\mathrm{c}} / P \ll 1$.

The results of scaling analysis using Eqs. (13) and (14) are summarized in Table 2. The diameter of the aggregates in the ice-slurry lahars was estimated as $d=0.26$ $-2.72 \mathrm{~mm}$, which corresponds to the diameters of granular snow and tephra. Additionally, the non-dimensional parameter for maintaining the aggregates was $F_{\mathrm{c}} / P \approx 10^{3}$ in our experiments, whereas that in the ice-slurry lahars was calculated as $F_{\mathrm{c}} / P=0.08-2.86$. These values suggest that the formation of the aggregates is impossible in the ice-slurry lahars. Note that the above scaling analysis has limitations because we did not consider system size parameters, such as water depth. If the size of the aggregates depends on the system size, different discussions would be needed.

\section{Conclusions}

This study aimed to elucidate the formation conditions of aggregates and their mechanical properties in threephase flow consisting of tephra, water, and snow. This research contributes to our understanding of the basic 
Table 2 Summary of scaling analysis

\begin{tabular}{|c|c|c|c|c|}
\hline References & $\rho_{\mathrm{b}}{ }^{\mathrm{a}}\left(\mathrm{kg} \mathrm{m}^{-3}\right)$ & $U\left(\mathrm{~m} \mathrm{~s}^{-1}\right)$ & $d(\mathrm{~mm})$ & $F_{\mathrm{c}} / P(-)$ \\
\hline This study & $991-1557$ & 0.113 & $\begin{array}{l}30 \text { (typical } \\
\text { case) }\end{array}$ & $1006-1580$ \\
\hline \multicolumn{5}{|c|}{ Snow slurry lahars (Cronin et al. 1996) } \\
\hline LH1 $(9.5$ km) & 470 & 5.5 & $1.30-2.04$ & 1.41 \\
\hline LH1 $(16$ km) & 540 & 3.6 & $1.73-2.72$ & 2.86 \\
\hline LH3 (9.5km) & 910 & 7.5 & $0.49-0.77$ & 0.39 \\
\hline \multicolumn{5}{|c|}{ Ice-slurry lahars (Lube et al. 2009) } \\
\hline $\begin{array}{c}\text { E1 (base of } \\
\text { glacier) }\end{array}$ & 650 & 20 & $0.26-0.41$ & 0.08 \\
\hline $\begin{array}{l}\text { E1 (monitor- } \\
\text { ing site) }\end{array}$ & 900 & 5 & $0.75-1.17$ & 0.89 \\
\hline
\end{tabular}

Bulk density, frontal speed, diameter of aggregates, and non-dimensional parameter for maintaining the aggregates are denoted by $\rho_{\mathrm{b}}, U, d$, and $F_{\mathrm{c}} / P$ respectively. $F_{c}$ is the effective compressive strength of aggregates, which was approximately constant independent of the size $\left(10^{4} \mathrm{~Pa}\right)$, and $P$ is the dynamic pressure as $\rho_{\mathrm{b}} U^{2} / 2$

a Data of deposits except this study

mechanism of lahars triggered by snowmelt. Mixing experiments of a three-phase material and compression tests of the resulting aggregates were conducted in a lowtemperature room at $0^{\circ} \mathrm{C}$. The aggregates reached maturity after a rotation time of $5 \mathrm{~min}$; however, the snow in the aggregates exhibited significant melting due to the heat of the rotating machine after $40 \mathrm{~min}$. The mass of the aggregate was proportional to the snow concentration because of the adhesion of snow. Single aggregates with large mass were observed at lower and higher tephra concentrations, whereas multiple aggregates with smaller mass were formed in the intermediate region of tephra concentration. Regarding the size of aggregates, the length, width, and height of the aggregates exhibited a proportional relationship, independent of the tephra diameter; however, aggregate size may have been confined by the water depth in the pot. The mass composition of tephra in the aggregates depended on only the tephra concentration and increased monotonically with the tephra concentration. Compression tests on the aggregates revealed a highly nonlinear stress-strain relationship, which was modeled by a combination of earlystage surface flattening and late-stage bulk compression processes. The former exhibited exponentially asymptotic behavior, whereas the latter exhibited exponential growth in the stress-strain relationship. In addition, the mechanical properties obtained by fitting to the proposed model were almost independent of the experimental conditions. A scaling analysis of our experiments with natural ice-slurry lahars was conducted based on the particle Reynolds number and the ratio of the strength of the aggregates divided by the dynamic pressure of the flows. According to the results, aggregates in nature are expected to have sizes of the millimeter scale and deform (or collapse) under dynamic pressure.

We believe that these findings are useful for understanding the dynamics of ice-slurry lahars. Ice-slurry lahars generally have been the high mobility attributable to snowmelt (Lube et al. 2009), but aggregate formation has been shown to reduce the mobility of mud

Table 3 List of mixing ratios among tephra, water, and snow

\begin{tabular}{|c|c|c|c|c|c|c|}
\hline$C_{\mathrm{t}}(\%)$ & $C_{\mathrm{s}}(\%)$ & $V_{\mathrm{t}}\left[\mathrm{cm}^{3}\right]([\mathrm{g}])$ & $V_{w}\left[\mathrm{~cm}^{3}\right]([\mathrm{g}])$ & $V_{\mathrm{s}}\left[\mathrm{cm}^{3}\right]([\mathrm{g}])$ & $V_{\text {total }}\left[\mathrm{cm}^{3}\right]([\mathrm{g}])$ & $\rho_{\mathrm{b}}\left(\mathrm{kg} \mathrm{m}^{-3}\right)$ \\
\hline \multicolumn{7}{|c|}{ EXP1-2 } \\
\hline 33 & 1 & $62.6(156.4)$ & $127.0(127.0)$ & $1.3(1.2)$ & 190.9 (284.6) & 1491 \\
\hline 33 & 5 & $60.9(152.1)$ & 123.5 (123.5) & $6.5(5.9)$ & 190.9 (281.6) & 1475 \\
\hline 33 & 9 & $59.1(147.7)$ & $120.0(120.0)$ & $11.9(10.8)$ & 190.9 (278.5) & 1459 \\
\hline 33 & 13 & $57.3(143.2)$ & $116.3(116.3)$ & $17.4(15.8)$ & 190.9 (275.2) & 1442 \\
\hline 33 & 17 & $55.4(138.5)$ & $112.5(112.5)$ & $23.0(21.0)$ & 190.9 (271.9) & 1424 \\
\hline \multicolumn{7}{|c|}{ EXP3-5 } \\
\hline 0 & 10 & $0(0)$ & 171.8 (171.8) & $19.1(17.4)$ & 190.9 (189.2) & 991 \\
\hline 1 & 10 & $1.7(4.3)$ & $170.3(170.3)$ & $18.9(17.2)$ & 190.9 (191.8) & 1005 \\
\hline 5 & 10 & $8.6(21.6)$ & $164.0(164.0)$ & $18.2(16.6)$ & $190.9(202.2)$ & 1059 \\
\hline 8 & 10 & 13.9 (34.6) & 159.3 (159.3) & $17.7(16.1)$ & $190.9(210.1)$ & 1101 \\
\hline 10 & 10 & $17.4(43.4)$ & $156.2(156.2)$ & $17.4(15.8)$ & 190.9 (215.4) & 1128 \\
\hline 15 & 10 & $26.2(65.4)$ & $148.3(148.3)$ & 16.5 (15.0) & 190.9 (228.7) & 1198 \\
\hline 20 & 10 & $35.1(87.7)$ & $140.3(140.3)$ & $15.6(14.2)$ & $190.9(242.1)$ & 1268 \\
\hline 25 & 10 & $44.1(110.1)$ & $132.2(132.2)$ & $14.7(13.4)$ & $190.9(255.7)$ & 1339 \\
\hline 30 & 10 & $53.1(132.8)$ & $124.0(124.0)$ & $13.8(12.5)$ & 190.9 (269.4) & 1411 \\
\hline 40 & 10 & $71.6(179.0)$ & $107.4(107.4)$ & $11.9(10.9)$ & $190.9(297.2)$ & 1557 \\
\hline
\end{tabular}


flows containing snow (Okita et al. 2018). Therefore, the dynamics of ice-slurry lahars potentially change depending on the amount of snowmelt, which leads to the dynamic complexity. We believe that the amount of melted or remnant snow and ice entrained by iceslurry lahars is an important factor in the discussion of the dynamics of ice-slurry lahars. Nevertheless, various issues still need to be addressed. For example, this study could not distinguish water from snow in the aggregate owing to technical difficulties; thus, the amount of snow in the aggregate (or the dispersion of snow in the flow) should be accurately measured in future work. Moreover, only granular snow with a diameter of 1-2 mm was used in this study. Therefore, different diameters and types of snow, such as fresh snow and compacted snow, should be considered. Furthermore, the experimental scale and the flow speed were extremely small compared to the lahars generated in mountainous areas; therefore, further research should confirm the formation of aggregates in flows of higher speeds with systems of larger scales. Finally, future work is planned to investigate the flow properties of three-phase flows involving tephra, water, and snow, such as viscosity coefficient, under conditions of snow aggregation and ice slurry.

\section{Abbreviations \\ Materials \\ $d_{t:}$ : Diameter of tephra $(\mu m) ; d_{s}$ : Diameter of snow $(\mu m) ; \rho_{t}$ : Material density of tephra $\left(\mathrm{g} \mathrm{cm}^{-3}\right) ; \rho_{\mathrm{w}}$ : Material density of water $\left(\mathrm{g} \mathrm{cm}^{-3}\right) ; \rho_{\mathrm{s}}$ : Material density of snow $\left(\mathrm{g} \mathrm{cm}^{-3}\right)$. \\ Mixing experiments using a glass pot \\ $V_{\text {total }}$ Total volume of materials: $V_{t}+V_{w}+V_{s}\left(\mathrm{~cm}^{-3}\right) ; V_{t}$ : Volume of tephra $\left(\mathrm{cm}^{-3}\right) ; V_{w}$ : Volume of water $\left(\mathrm{cm}^{-3}\right) ; V_{\mathrm{s}}:$ Volume of snow $\left(\mathrm{cm}^{-3}\right) ; C_{\mathrm{t}}$ :Tephra concentration: $V_{t} /\left(V_{t}+V_{w}\right) \times 100(\%) ; C_{s}$ : Snow concentration: $V_{s} /\left(V_{s}+V_{w}\right) \times 100(\%) ; \omega$ : Angular speed of pot $\left(\mathrm{rad} \mathrm{s}^{-1}\right)$; $t$ : Rotation time of pot (min).}

\section{Flow conditions}

$D_{\text {w: }}$ Maximum water depth of mixture in pot at static state $(\mathrm{cm}) ; A_{\text {pot: }}$ Crosssectional area of pot $\left(\mathrm{cm}^{2}\right)$; $A_{\text {mixture: }}$ Cross-sectional area of mixture $\left(\mathrm{cm}^{2}\right) ; r$ : Radius of pot (cm); Fr: Froude number: $v / \sqrt{D_{w} g} ; v$ : Rotating speed of pot wall $\left(\mathrm{cm} \mathrm{s}^{-1}\right) ; \mathrm{g}$ : Gravitational acceleration $\left(\mathrm{m} \mathrm{s}^{-2}\right)$.

\section{Heat transfer}

$\theta$ : Air temperature around rotating table $\left({ }^{\circ} \mathrm{C}\right) ; \theta_{\text {Initial }}$ Air temperature before rotating the pot $\left({ }^{\circ} \mathrm{C}\right) ; \theta_{\text {End }}$ : Air temperature after rotating the pot $\left({ }^{\circ} \mathrm{C}\right) ; \mathrm{Q}$ : Amount of heat transport $(J)$; $h$ : Heat transfer coefficient $\left(\mathrm{W} \mathrm{m}^{-2} \mathrm{~K}^{-1}\right)$; $A$ : Cross-sectional area of passage $\left(\mathrm{m}^{2}\right) ; \Delta \theta$ : Temperature difference $\left(\mathrm{K}\right.$ or $\left.{ }^{\circ} \mathrm{C}\right) ; \theta_{\text {ave: }}$ : Time-averaged air temperature: $\left(\theta_{\text {|nitial }}+\theta_{\text {End }}\right) / 2\left({ }^{\circ} \mathrm{C}\right)$.

\section{Aggregates}

$N$ : Number of aggregates; $m$ : Mass of aggregate (g); L: Length of aggregate $(\mathrm{cm}) ; W$ : Width of aggregate: $L \geq W(\mathrm{~cm}) ; H$ : Height of aggregate $(\mathrm{cm}) ; m_{\mathrm{t}}$ : Mass composition of tephra in aggregate $(\mathrm{g}) ; m_{\mathrm{w}}$ : Mass composition of water in aggregate $(\mathrm{g})$; $m_{\mathrm{s}}$ : Mass composition of snow in aggregate $(\mathrm{g}) ; \mathrm{w}_{\mathrm{t}}$ : Mass fraction of tephra in aggregate: $m_{t} / m$.

\section{Compression test}

F: Compression force ( $\mathrm{N}) ; \delta$ : Compression stroke $(\mathrm{mm})$; $S$ : Effective area of aggregate using elliptic approximation $\left(\mathrm{cm}^{2}\right)$; V:Volume of aggregate using elliptic approximation $\left(\mathrm{cm}^{3}\right) ; \tau$ : Stress: $F / S(k P a) ; \gamma$ : Strain: $\delta / H ; E_{\mathrm{b}}$ : Effective bulk compression modulus ( $\mathrm{kPa}$ ); $R_{\mathrm{s}}$ : Ratio of compressive moduli between bulk and surface deformation; $\gamma_{b}$ : Characteristic strain for bulk compression; $\gamma_{\mathrm{s}}$ : Characteristic strain for surface-roughness compression; $F_{c}$ : Effective compressive strength of aggregates: $E_{\mathrm{b}} / \gamma_{\mathrm{b}}(\mathrm{kPa})$.

\section{Scaling analysis}

$R e_{\mathrm{p}}$ : Particle Reynolds number: $\rho_{\mathrm{b}} U d / \mu ; \rho_{\mathrm{b}}$ : Bulk density of flow $\left(\mathrm{kg} \mathrm{m}^{-3}\right) ; \mathrm{U}$ : Frontal speed of flow $\left(\mathrm{m} \mathrm{s}^{-1}\right)$; $\mu$ : Viscosity coefficient of flow (Pa s); d: Diameter of aggregate $(\mathrm{mm}) ; F_{\mathrm{c}} / P$ : Non-dimensional parameter to keep aggregate; $P$ : Dynamic pressure of flow: $\rho_{b} U^{2} / 2(\mathrm{kPa})$.

\section{Acknowledgements}

The authors wish to thank Ryuma Okita (Niigata University), Kazuya Egawa (Nagoya University), Soichiro Sato, Satoshi Yamagami, Tatsuya Kagakui, Yugo Kojima, and Naoki Sueyoshi (Nihon University), who participated in the experiments. We thank Editage (http://www.editage.com) for English language editing. We would like to thank 2 reviewers for carefully reading our manuscript and providing constructive comments.

\section{Authors' contributions}

HN analyzed and interpreted the experimental data regarding the formation conditions of aggregates and significantly contributed to writing the manuscript. KO performed mixing experiments of materials and compiled the experimental data. DT conducted compression tests of aggregates and proposed an empirical model for the compressive mechanics. HK interpreted the experimental data regarding the mechanical properties of aggregates and helped write the manuscript. All authors participated in low-temperature experiments and improved the experimental system. All authors read and approved the final manuscript.

\section{Funding}

This research was supported by the Collaborative Research Project (2018-2, 2019-1, 2020-1) of the Research Institute for Natural Hazards and Disaster Recovery, Niigata University.

\section{Availability of data and materials}

The datasets used and analyzed during the current study are available from the corresponding author on reasonable request.

\section{Competing interests}

The authors declare that they have no competing interests.

\section{Author details}

${ }^{1}$ Center for Transdisciplinary Research, Niigata University, 8050 Ikarashi 2-no-cho, Nishi-ku, Niigata 950-2181, Japan. ${ }^{2}$ Department of Civil Engineering, College of Science and Technology, Nihon University, 1-8-14 Kanda-Surugadai, Chiyoda-ku, Tokyo 101-8308, Japan. ${ }^{3}$ Department of Earth and Environmental Sciences, Nagoya University, Nagoya 464-8601, Japan. ${ }^{4}$ Department of Earth and Space Science, Osaka University, 1-1 Machikaneyama, Toyonaka 560-0043, Japan.

\section{Appendix: List of volumes and masses of tephra, water, and snow}

As shown in Table 1, we determined the mixing ratio among tephra, water, and snow based on the tephra and snow concentrations, $C_{\mathrm{t}}$ and $C_{\mathrm{s}}$, defined by Eqs. (1, 2). The volume of water $V_{\mathrm{w}}$ was derived from Eqs. (1, 2) as a function of $C_{\mathrm{t}}, C_{\mathrm{s}}$, and the total volume $V_{\text {total }}$; additionally, the volumes of tephra and snow, $V_{\mathrm{t}}$ and $V_{\mathrm{s}}$, were derived from Eqs. $(1,2)$, respectively, 


$$
\begin{aligned}
& V_{\mathrm{w}}=V_{\mathrm{total}} \frac{\left(1-C_{\mathrm{t}}\right)\left(1-C_{\mathrm{s}}\right)}{1-C_{\mathrm{t}} C_{\mathrm{s}}}, \\
& V_{\mathrm{t}}=V_{\mathrm{w}} \frac{C_{\mathrm{t}}}{1-C_{\mathrm{t}}}, \\
& V_{\mathrm{s}}=V_{\mathrm{w}} \frac{C_{\mathrm{s}}}{1-C_{\mathrm{s}}} .
\end{aligned}
$$

We measured the masses of tephra, water, and snow as the volumes calculated in Eqs. (15-17) times the material densities. In this study, $\rho_{\mathrm{t}}, \rho_{\mathrm{w}}$, and $\rho_{\mathrm{s}}$ were $2.50 \mathrm{~g} \mathrm{~cm}^{-3}$, $1.00 \mathrm{~g} \mathrm{~cm}^{-3}$, and $0.91 \mathrm{~g} \mathrm{~cm}^{-3}$, respectively. The volume (mass) of each material and the bulk density $\rho_{\mathrm{b}}$ in the experimental conditions of EXP1-5 are listed in Table 3.

Received: 13 July 2020 Accepted: 4 October 2020

Published online: 16 October 2020

\section{References}

Calhoun NC, Clague JJ (2018) Distinguishing between debris flows and hyperconcentrated flows: an example from the eastern Swiss Alps. Earth Surf Process Landforms 43:1280-1294. https://doi.org/10.1002/ esp.4313

Cronin SJ, Neall VE, Lecointre HA, Palmer AS (1996) Unusual "snow slurry" lahars from Ruapehu volcano, New Zealand, September 1995. Geology 24:1107-1110. https://doi.org/10.1130/00917613(1996)024<1107:USSLFR>2.3.CO;2

Fischer J-T, Kaitna R, Heil K, Reiweger I (2018) The heat of the flow: thermal equilibrium in gravitational mass flows. Geophys Res Lett 45:11,21911,226. https://doi.org/10.1029/2018GL079585

Kataoka KS, Matsumoto T, Saito T, Kawashima K, Nagahashi Y, lyobe T, Sasaki A, Suzuki K (2018) Lahar characteristics as a function of triggering mechanism at a seasonally snow-clad volcano: contrasting lahars following the 2014 phreatic eruption of Ontake Volcano, Japan. Earth Planets Space 70:113. https://doi.org/10.1186/s40623-018-0873-x

Kataoka KS, Matsumoto T, Saito T, Nagahashi Y, lyobe T (2019) Suspended sediment transport diversity in river catchments following the 2014 phreatic eruption at Ontake Volcano, Japan. Earth Planets Space 71:15. https://doi.org/10.1186/s40623-019-0994-x

Klute A (1986) Water retention: laboratory methods. In: Klute A (ed) Methods of soil analysis: part 1 physical and mineralogical methods. Soil Science Society of America, American Society of Agronomy, Madison
Lube G, Cronin SJ, Procter JN (2009) Explaining the extreme mobility of volcanic ice-slurry flows, Ruapehu volcano, New Zealand. Geology 37:15-18. https://doi.org/10.1130/G25352A.1

Major JJ, Newhall CG (1989) Snow and ice perturbation during historical volcanic eruptions and the formation of lahars and floods. Bull Volcanol 52:1-27. https://doi.org/10.1007/BF00641384

Miwa S (1970) Measurement of powder characteristics (II). J Soc Mater Sci Jpn 19:476-483. https://doi.org/10.2472/jsms.19.476 (in Japanese)

Okita R, Kawashima K, Matsumoto T, Kataoka KS, Watabe S (2018) Influence of snow on the fluidity of lahars triggered by snowmelt. In: Proceedings of cold region technology conference 34:I-007 (in Japanese)

Pierson TC (1995) Flow characteristics of large eruption-triggered debris flows at snow-clad volcanoes: constraints for debris-flow models. J Volcanol Geotherm Res 66:283-294. https://doi.org/10.1016/0377-0273(94)00070 $-\mathrm{W}$

Pierson TC (2005) Hyperconcentrated flow-transitional process between water flow and debris flow. Debris-flow hazards and related phenomena. Springer Praxis Books. Springer, Berlin. https://doi.org/10.1007/3-54027129-5_8

Pierson TC, Scott KM (1985) Downstream dilution of a lahar: transition from debris flow to hyperconcentrated streamflow. Water Resour Res 21:1511-1524. https://doi.org/10.1029/WR021i010p01511

Pierson TC, Janda RJ, Thouret J-C, Borrero CA (1990) Perturbation and melting of snow and ice by the 13 November 1985 eruption of Nevado del Ruiz, Colombia, and consequent mobilization, flow and deposition of lahars. JVolcanol Geotherm Res 41:17-66. https://doi.org/10.1016/03770273(90)90082-Q

Tada F, Tsuya H (1927) The eruption of the Tokachidake volcano, Hokkaido, on May 24th, 1926. Bull Earthq Res Inst Univ Tokyo 2:49-85 (in Japanese)

Uesawa S (2014) A study of the Taisho lahar generated by the 1926 eruption of Tokachidake Volcano, central Hokkaido, Japan, and implications for the generation of cohesive lahars. J Volcanol Geotherm Res 270:23-34. https ://doi.org/10.1016/j.jvolgeores.2013.11.002

Waythomas CF (2014) Water, ice and mud: lahars and lahar hazards at ice- and snow-clad volcanoes. Geol Today 30:34-39. https://doi.org/10.1111/ gto. 12035

Waythomas CF, Pierson TC, Major JJ, Scott WE (2013) Voluminous ice-rich and water-rich lahars generated during the 2009 eruption of Redoubt Volcano, Alaska. J Volcanol Geotherm Res 259:389-413. https://doi. org/10.1016/j.jvolgeores.2012.05.012

Weisstein EW (2020) "Circular segment." From MathWorld-A Wolfram Web Resource. https://mathworld.wolfram.com/CircularSegment.html. Accessed 12 June 2020

\section{Publisher's Note}

Springer Nature remains neutral with regard to jurisdictional claims in published maps and institutional affiliations.

\section{Submit your manuscript to a SpringerOpen ${ }^{\circ}$ journal and benefit from:}

- Convenient online submission

- Rigorous peer review

- Open access: articles freely available online

- High visibility within the field

- Retaining the copyright to your article

Submit your next manuscript at springeropen.com 